\title{
Properties of $\mathrm{Nag}^{\wedge *}$ s Closed Sets in Topological Spaces
}

\author{
${ }^{1}$ M. Dharani ${ }^{2}$ V. Senthilkumaran and ${ }^{3} Y$. Palaniappan \\ * M.Phil Scholar, Aringar Anna Government Arts college, Musiri-621211, Tamilnadu, India. \\ ** Associate Professor of Mathematics, Aringar Anna Government Arts college, Musiri-621211, Tamilnadu, India. \\ *** Associate Professor of Mathematics (Retd), Aringar Anna Government Arts college, Musiri-621211, Tamilnadu, India. \\ DOI: 10.29322/IJSRP.11.10.2021.p11873 \\ http://dx.doi.org/10.29322/IJSRP.11.10.2021.p11873
}

\begin{abstract}
In this paper, we investigate $\mathrm{N} \alpha g^{*}$ s closure and $\mathrm{N} \alpha g^{*}$ s interior. Also we study $\mathrm{N} T^{*} \alpha g s$ space and its relation to various other
\end{abstract} spaces.

Index Terms- nano toplogy, $\mathrm{N} \alpha \mathrm{g}^{\wedge *} \mathrm{~s}$ closed set, $\mathrm{NT}^{\wedge *} \alpha \mathrm{gs}$ space.

2010 AMS subject classification: 54B05,54C05.

\section{INTRODUCTION}

L ellis Thivagar etal [3] introduced a nano topological space with respect to a subset $\mathrm{X}$ of an universe which is defined in terms of lower and upper approximations of X. The elements of a nano topological space are called nano open sets. 'Nano' is a Greek word which means 'very small'. The topology studied here is given the name nano topology as it has utmost five elements. Certain weak forms of nano sets were studied by arious authors. Njastad [7] and Mashour etal [6] investigated the concept of $\alpha$ open and $\alpha$ closed sets respectively in topological spaces. The generalized closed (briefly g closed) sets were analyzed by Levine [5]. Arya and Nour [1] introduced and studied weaker forms of closed sets namely, generalized semi closed (briefly gs closed) sets using open sets. T.D. Rayanagoudar[8] introduce a new class of closed sets, called $\alpha g^{*}$ semi closed (briefly $\alpha g^{*}$ s closed) sets using gs open sets in topological spaces.

In this paper we study $\mathrm{N} \alpha g^{*}$ s closure and $\mathrm{N} \alpha g^{*}$ s interior and some applications of $\mathrm{N} \alpha g^{*}$ s closed sets.

\section{PRELIMINARIES}

Definition 2.1: [3] Let $\mathcal{U}$ be a non-empty finite set of objects called the universe and $\mathrm{R}$ be an equivalence relation on $\mathcal{U}$ named as the indiscernibility relation. Elements belonging to the same equivalence class are said to be indiscernible with one another. The pair $(U, R)$ is said to be the approximation space. Let $\mathrm{X} \subseteq \mathcal{U}$.

(i) The lower approximation of $\mathrm{X}$ with respect to $\mathrm{R}$ is the set of all objects, which can be for certain classified as $\mathrm{X}$ with respect to $\mathrm{R}$ and it is denoted by $L_{R}(X)$. That is, $L_{R}(X)=\underset{x \in \mathcal{U}}{U}\{R(x): R(x) \subseteq X\}$, where $\mathrm{R}(\mathrm{x})$ denotes the equivalence class determined by $\mathrm{x}$.

(ii) The upper approximation of $\mathrm{X}$ with respect to $\mathrm{R}$ is the set of all objects, which can be possibly classified as $\mathrm{X}$ with respect to $\mathrm{R}$ and it is denoted by $U_{R}(X)$. That is, $U_{R}(X)=\underset{x \in \mathcal{U}}{U}\{R(x): R(x) \cap X \neq \emptyset\}$.

(iii) The boundary region of $X$ with respect to $\mathrm{R}$ is the set of all objects, which can be classified neither as $\mathrm{X}$ nor as not- $\mathrm{X}$ with respect to $\mathrm{R}$ and it is denoted by $B_{R}(X)$. That is $B_{R}(X)=U_{R}(X)-L_{R}(X)$.

Definition 2.2:[3] let $\mathcal{U}$ be the universe, $\mathrm{R}$ be an equivalence relation on $\mathcal{U}$ and $\tau_{R}(\mathrm{X})=\left\{\mathcal{U}, \varphi, L_{R}(X), U_{R}(X), B_{R}(X)\right\}$, where $\mathrm{X} \subseteq \mathcal{U}$. $\tau_{R}(\mathrm{X})$ satisfies the following axioms.

i) $\quad \mathcal{U}$ and $\varphi \in \tau_{R}(X)$.

ii) The union of the elements of any subcollection of $\tau_{R}(\mathrm{X})$ is in $\tau_{R}(\mathrm{X})$.

iii) The intersection of the elements of any finite subcollection of $\left.\tau_{R} \mathrm{X}\right)$ is in $\tau_{R}(\mathrm{X})$.

That is, $\tau_{R}(\mathrm{X})$ forms a topology on $U$ called as the nano topology on $U$ with respect to $\mathrm{X}$. We call $\left(\mathcal{U}, \tau_{R}(\mathrm{X})\right)$ as the nano topological space. The elements of $\tau_{R}(\mathrm{X})$ are called as nano-open sets. A set $\mathrm{A}$ is said to be nano closed if its complement is nano-open.

Definition 2.3: [3] If $\left(\mathcal{U}, \tau_{R}(\mathrm{X})\right)$ is a nano topological space with respect to $\mathrm{X}$ where $\mathrm{X} \subseteq \mathcal{U}$ and if $\mathrm{A} \subseteq \mathcal{U}$, then the nano interior of $\mathrm{A}$ is defined as the union of all nano-open subsets of $A$ and it is denoted by $\operatorname{Nint}(A)$. That is, $\operatorname{Nint}(\mathrm{A})$ is the largest nano-open subset of $\mathrm{A}$. 
The nano closure of $\mathrm{A}$ is defined as the intersection of all nano closed sets containing $\mathrm{A}$ and it is denoted by $\mathrm{Ncl}(\mathrm{A})$. That is, $\mathrm{Ncl}(\mathrm{A})$ is the smallest nano closed set containing A.

Definition 2.4: A nano subset $\mathrm{A}$ of a nano topological space $\left(\mathcal{U}, \tau_{R}(\mathrm{X})\right)$ is called a

1. Nano pre closed if $\operatorname{Ncl} \operatorname{Nint}(\mathrm{A}) \subseteq A$

2. Nano semi closed if $\operatorname{Nint} \operatorname{Ncl}(\mathrm{A}) \subseteq A$

3. Nano $\alpha$ closed if $\operatorname{Ncl} \operatorname{Nint} \operatorname{Ncl}(\mathrm{A}) \subseteq A$

4. Nano semi pre closed if $\operatorname{Nint} \operatorname{Ncl} \operatorname{Nint}(\mathrm{A}) \subseteq A$

5. Nano regular closed if $\operatorname{Ncl} \operatorname{Nint}(\mathrm{A})=A$

For a nano subset $\mathrm{A}$ of $\left(\mathcal{U}, \tau_{R}(\mathrm{X})\right)$ the intersection of all nano pre closed. (nano semi closed, nano $\alpha$ closed, nano semi pre closed) sets of $\left(\mathcal{U}, \tau_{R}(\mathrm{X})\right)$ containing $\mathrm{A}$ is called nano pre closure of $\mathrm{A}$ (nano semi closure of $\mathrm{A}$, nano $\alpha$ closure of $\mathrm{A}$, nano semi pre closure of $\mathrm{A}$ ) and is denoted by $\operatorname{Npcl}(\mathrm{A})(\operatorname{Nscl}(\mathrm{A}), \operatorname{N\alpha cl}(\mathrm{A}), \operatorname{Nspcl}(\mathrm{A}))$.

Definition 2.5: A nano subset $\mathrm{A}$ of a nono topological space $\left(\mathcal{U}, \tau_{R}(\mathrm{X})\right)$ is called a

1. Nano generalized closed (briefly $\mathrm{Ng}$ closed) if $\operatorname{Ncl}(\mathrm{A}) \subseteq U$, whenever $\mathrm{A} \subseteq U$ and $\mathrm{U}$ is nano open in $\mathcal{U}$.

2. Nano generalized semi closed (briefly $\mathrm{Ngs}$ closed) if $\operatorname{Nscl}(\mathrm{A}) \subseteq U$ whenever $\mathrm{A} \subseteq U$ and $\mathrm{U}$ is nano open in $\mathcal{U}$.

3. Nano $\alpha$ generalized regular closed (briefly $N \alpha$ gr closed) if $\operatorname{Nocl}(\mathrm{A}) \subseteq U$ whenever $\mathrm{A} \subseteq U$ and $U$ is nano regular open in $\mathcal{U}$.

4. Nano $\alpha$ generalized semi closed (briefly $\mathrm{N} \alpha g$ s closed) if $\operatorname{Nocl}(\mathrm{A}) \subseteq U$ whenever $\mathrm{A} \subseteq U$ and $\mathrm{U}$ is nano semi open in $\mathcal{u}$.

5. Nano $\alpha$ generalized closed (briefly $N \alpha$ closed) if $\operatorname{Nocl}(\mathrm{A}) \subseteq U$ whenever $\mathrm{A} \subseteq U$ and $\mathrm{U}$ is nano open in $\mathcal{U}$.

6. Nano generalized semi pre closed (briefly $\operatorname{Ngsp}$ closed) if $\operatorname{Nspcl}(\mathrm{A}) \subseteq U$ whenever $\mathrm{A} \subseteq U$ and $\mathrm{U}$ is nano open in $\mathcal{U}$.

7. Nano generalized pre closed (briefly $\operatorname{Ngp}$ closed) if $\operatorname{Npcl}(\mathrm{A}) \subseteq U$ whenever $\mathrm{A} \subseteq U$ and $\mathrm{U}$ is nano open in $\mathcal{U}$.

8. Nano $g^{*}$ pre closed (briefly $\mathrm{Ng}^{*}$ p closed) if $\operatorname{Npcl}(\mathrm{A}) \subseteq U$ whenever $\mathrm{A} \subseteq U$ and $U$ is $\mathrm{Ng}$ open in $\mathcal{U}$.

9. Nano generalized pre regular closed (briefly $\mathrm{Ngpr}$ closed) if $\operatorname{Npcl}(\mathrm{A}) \subseteq U$ whenever $\mathrm{A} \subseteq U$ and $U$ is nano regular open in $\mathcal{U}$.

10. Nano semi generalized closed (briefly Nsg closed) if $\operatorname{Nscl}(\mathrm{A}) \subseteq U$ whenever $\mathrm{A} \subseteq U$ and $\mathrm{U}$ is nano semi open in $\mathcal{U}$.

11. Nano $g^{\#} \alpha$ closed (briefly $\mathrm{Ng}^{\#} \alpha$ closed) if $\mathrm{N} \alpha \mathrm{cl}(\mathrm{A}) \subseteq U$ whenever $\mathrm{A} \subseteq U$ and $\mathrm{U}$ is $\mathrm{Ng}$ open in $\mathcal{U}$.

12. Nano $g^{\#} S$ closed (briefly $\mathrm{N}^{\#} s$ closed) if $\mathrm{Nscl}(\mathrm{A}) \subseteq U$ whenever $\mathrm{A} \subseteq U$ and $\mathrm{U}$ is $\mathrm{N} \alpha \mathrm{g}$ open in $\mathcal{U}$.

The complements of the above mentioned nano closed sets are respective nano open sets.

Definition 2.6: A nano topological space $\left(\mathcal{U}, \tau_{R}(\mathrm{X})\right)$ is said to be a

1. Nano semi $T_{\frac{1}{2}}$ space if every Nsg closed set is nano semi closed.

2. $\mathrm{N} T_{b}$ space if every $\mathrm{Ngs}$ closed set of $\left(\mathcal{U}, \tau_{R}(\mathrm{X})\right)$ is nano closed in $\left(\mathcal{U}, \tau_{R}(\mathrm{X})\right)$.

3. $N_{\alpha} T_{b}$ space if every $\mathrm{N} \alpha \mathrm{g}$-closed set of $\left(\mathcal{U}, \tau_{R}(\mathrm{X})\right)$ is nano closed in $\left(\mathcal{U}, \tau_{R}(\mathrm{X})\right)$.

4. $N T_{b}^{*}$ - space if every $\mathrm{Ng}^{*}$ s- closed set of $\left(\mathcal{U}, \tau_{R}(\mathrm{X})\right)$ is nano closed in $\left(\mathcal{U}, \tau_{R}(\mathrm{X})\right)$.

5. $T_{b}^{* *}$ - space if every $\mathrm{Ng}^{*}$ s- closed set of $\left(\mathcal{U}, \tau_{R}(\mathrm{X})\right)$ is $\mathrm{N} \alpha$ closed in $\left(\mathcal{U}, \tau_{R}(\mathrm{X})\right)$.

\section{3. N $\alpha \boldsymbol{g}^{*}$ S CLOSURE AND N $\boldsymbol{\alpha} \boldsymbol{g}^{*} \mathrm{~S}$ INTERIOR}

Definition:3.1 A subset A of a nano topological space $\left(\mathcal{U}, \tau_{R}(\mathrm{X})\right)$ is said to be $\mathrm{N} \alpha g^{*}$ semi closed (briefly $\mathrm{N} \alpha g^{*} \mathrm{~s}$ closed) set if $\mathrm{N} \alpha \mathrm{cl}(\mathrm{A})$ $\subseteq \mathrm{U}$, whenever $\mathrm{A} \subseteq \mathrm{U}$ and $\mathrm{U}$ is $\mathrm{Ngs}$ open in $\left(\mathcal{U}, \tau_{R}(\mathrm{X})\right)$.

Definition: 3.2 For a subset A of $\left(\mathcal{U}, \tau_{R}(\mathrm{X})\right), N \alpha g^{*} \mathrm{~s}-\operatorname{closure}$ of $\mathrm{A}$, denoted by $\operatorname{N\alpha } g^{*} \operatorname{scl}(\mathrm{A})$ and is defined as $\mathrm{N} \alpha g^{*} \operatorname{scl}(\mathrm{A})=$ $\cap\left\{G: A \subseteq G, G\right.$ is $\mathrm{N \alpha g}^{*} \mathrm{~s}-$ closed in $\left.\left(\mathcal{U}, \tau_{R}(\mathrm{X})\right)\right\}$.

Theorem :3.3 For any $\mathrm{x} \in X, x \in \mathrm{N} \alpha g^{*} \operatorname{scl}(\mathrm{A})$ if and only if $\mathrm{A} \cap V \neq \varphi$ for every $\mathrm{N} \alpha g^{*}$ s- open set $\mathrm{V}$ containing $\mathrm{x}$.

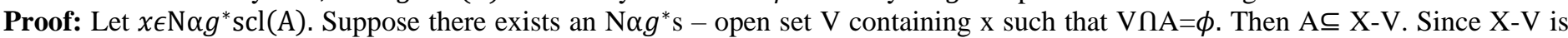

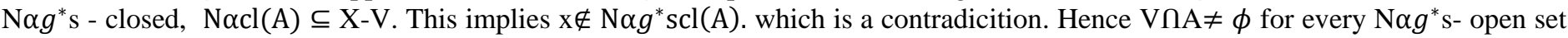
$\mathrm{V}$ containing $\mathrm{x}$.

Conversely, let $\mathrm{A} \cap \mathrm{V} \neq \phi$ for every $\mathrm{N}_{\alpha} g^{*} \mathrm{~s}$ - open set $\mathrm{V}$ containing $\mathrm{x}$. To prove that $x \in \mathrm{N} \alpha g^{*} \operatorname{scl}(\mathrm{A})$. Suppose $\mathrm{x} \notin \mathrm{N} \alpha g^{*} \operatorname{scl}(\mathrm{A})$. Then there

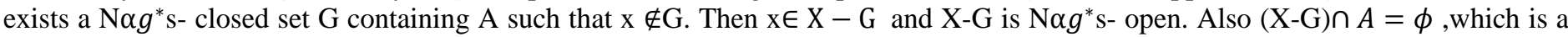
contradiction to the hypothesis. Hence $x \in \mathrm{N} \alpha g^{*} \operatorname{scl}(\mathrm{A})$.

Theorem :3.4 If $\mathrm{A} \subseteq \mathrm{X}$, then $\mathrm{A} \subseteq \mathrm{N \alpha} g^{*} \operatorname{scl}(\mathrm{A}) \subseteq \operatorname{Ncl}(A)$.

Proof: Since every nano closed set is ${\mathrm{N} \alpha g^{*}}^{*}$ - closed, the proof follows.

Remark:3.5 Both containment relations in the theorem 3.3 may be proper as seen from the following example. 
Example 3.6: Let $\mathcal{U}=\{a, b, c\}, \mathcal{U} / \mathrm{R}=\{\{a, b\},\{c\}\}, \mathrm{X}=\{a, b\}, \tau_{R}(\mathrm{X})=\{\mathcal{U}, \varphi,\{a, b\}\}$. Let $\mathrm{E}=\{a\}, \operatorname{N} \alpha g^{*} \mathrm{cl}(\mathrm{E})=\{a, c\}, \operatorname{Ncl}(\mathrm{E})=\mathcal{U}$. So, the containment may be proper.

Theorem: 3.7 Let $\mathrm{E}$ and $\mathrm{F}$ be subsets of $\left(\mathcal{U}, \tau_{R}(\mathrm{X})\right)$, then

a) $\mathrm{N \alpha g} g^{*} \operatorname{scl}(\phi)=\phi$.

b) $\mathrm{N \alpha g}{ }^{*} \operatorname{scl}(X)=X$.

c) $\mathrm{N} \alpha g^{*} \mathrm{scl}(E)$ is $\mathrm{N} \alpha g^{*} \mathrm{~s}$ - closed set in $\left(U, \tau_{R}(\mathrm{X})\right)$.

d) If $\mathrm{E} \subseteq \mathrm{F}$, then $\mathrm{N} \alpha g^{*} \mathrm{scl}(E) \subseteq \mathrm{N} \alpha g^{*} \operatorname{scl}(F)$.

e) $\mathrm{N} \alpha g^{*} \operatorname{scl}(E U F)=\mathrm{N} \alpha g^{*} \operatorname{scl}(E) \mathrm{U} \mathrm{N \alpha} g^{*} \operatorname{scl}(F)$.

f) $\mathrm{N} \alpha g^{*} \mathrm{scl}\left[\mathrm{N} \alpha g^{*} \operatorname{scl}(E)\right]=\mathrm{N} \alpha g^{*} \operatorname{scl}(E)$.

Proof: The proof of a), b), c) and d) follow from the definition 3.1.

e) To prove that $\mathrm{N} \alpha g^{*} \operatorname{scl}(E) \mathrm{U} \mathrm{N \alpha} g^{*} \operatorname{scl}(F) \subseteq \mathrm{N} \alpha g^{*} \operatorname{scl}(E U F)$

we have $\mathrm{N} \alpha g^{*} \operatorname{scl}(E) \subseteq \mathrm{N} \alpha g^{*} \operatorname{scl}(E U F)$ and

$\mathrm{N \alpha} g^{*} \operatorname{scl}(F) \subseteq \mathrm{N \alpha} g^{*} \operatorname{scl}(E U F)$

Therefore $\mathrm{N} \alpha g^{*} \operatorname{scl}(E) \mathrm{U} \mathrm{N \alpha} g^{*} \operatorname{scl}(F) \subseteq \mathrm{N} \alpha g^{*} \operatorname{scl}(E U F)$

Now, we prove $\mathrm{N} \alpha g^{*} \operatorname{scl}(E U F) \subseteq \mathrm{N} \alpha g^{*} \operatorname{scl}(E) \mathrm{U} \mathrm{N} \alpha g^{*} \operatorname{scl}(F)$.

Let $\mathrm{x}$ be any point such that $\mathrm{x} \notin \mathrm{N} \alpha g^{*} \operatorname{scl}(E) \mathrm{U} \mathrm{N} \alpha g^{*} \operatorname{scl}(F)$.

Then there exists $N \alpha g^{*}$ s- closed sets $\mathrm{A}$ and $\mathrm{B}$ such that $\mathrm{E} \subseteq \mathrm{A}$ and $\mathrm{F} \subseteq \mathrm{B}, \mathrm{x} \notin \mathrm{A}$ and $\mathrm{x} \notin \mathrm{B}$. Then $\mathrm{x} \notin \mathrm{AUB}, \mathrm{EUF} \subseteq \mathrm{AUB}$ and AUB is $\mathrm{N} \alpha g^{*}$ s- closed set. Thus $\mathrm{x} \notin \mathrm{N} \alpha g^{*} \mathrm{scl}(\mathrm{EUF})$.

Therefore we have $\mathrm{N} \alpha g^{*} \operatorname{scl}(E U F) \subseteq \mathrm{N} \alpha g^{*} \operatorname{scl}(E) \mathrm{U} \mathrm{N} \alpha g^{*} \operatorname{scl}(F) \ldots \ldots \ldots . .(2)$

Hence from (1) and (2), $\mathrm{N} \alpha g^{*} \operatorname{scl}(E U F)=\mathrm{N} \alpha g^{*} \operatorname{scl}(E) \mathrm{U} \mathrm{N \alpha} g^{*} \operatorname{scl}(F)$.

f) Let A be $\mathrm{N} \alpha g^{*}$ s- closed set containing E. Then by definition $\mathrm{N} \alpha g^{*} \operatorname{scl}(\mathrm{E}) \subseteq \mathrm{A}$.

Since A is $\mathrm{N} \alpha g^{*}$ s- closed set and contains $\mathrm{N} \alpha g^{*} \mathrm{scl}(E)$ and is contained in every $\mathrm{N} \alpha g^{*}$ s- closed set containing E, it follows that $\mathrm{N} \alpha g^{*} \mathrm{scl}$ $\left[\mathrm{N} \alpha g^{*} \operatorname{scl}(E)\right] \subseteq \mathrm{N} \alpha g^{*} \operatorname{scl}(E)$. Therefore $\mathrm{N} \alpha g^{*} \operatorname{scl}\left[\mathrm{N} \alpha g^{*} \operatorname{scl}(E)\right]=\operatorname{N\alpha } g^{*} \operatorname{scl}(E)$.

Theorem: $3.8 \mathrm{~N} \alpha g^{*} \mathrm{~s}-$ closure is a Kuratowski closure operator on $\left(\mathcal{U}, \tau_{R}(\mathrm{X})\right)$.

Proof: Follows from the theorem 3.6

Remark:3.9 A subset A is $\mathrm{N} \alpha g^{*} \mathrm{~s}-$ closed if and only if $\mathrm{N} \alpha g^{*} \operatorname{scl}(A)=\mathrm{A}$.

Proof: Let A be $\mathrm{N} \alpha g^{*}$ s- closed set in $\left(U, \tau_{R}(\mathrm{X})\right)$. Since $\mathrm{A} \subseteq \mathrm{A}$ and $\mathrm{A}$ is $\mathrm{N} \alpha g^{*}$ s- closed set, $\mathrm{A} \in\left\{G: A \subseteq G, G\right.$ is $\mathrm{N} \alpha g^{*} \mathrm{~s}-$ closed set $\}$ which implies that $\cap\left\{G: A \subseteq G, G\right.$ is $\mathrm{N} \alpha g^{*} \mathrm{~s}-$ closed set $\} \subseteq A$. That is $\mathrm{N} \alpha g^{*} \operatorname{scl}(A) \subseteq \mathrm{A}$. Note that $\mathrm{A} \subseteq \mathrm{N} \alpha g^{*} \operatorname{scl}(A)$ is always true. Hence $\mathrm{A}=\mathrm{N \alpha} g^{*} \operatorname{scl}(A)$.

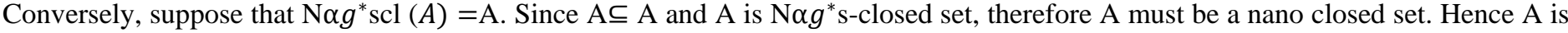
$\mathrm{N} \alpha g^{*}$ s- closed.

Definition :3.10 For a subset A of $\left(\mathcal{U}, \tau_{R}(\mathrm{X})\right), \mathrm{N} \alpha g^{*}$ s -interior of A, denoted by $\mathrm{N} \alpha g^{*} \operatorname{sint}(\mathrm{A})$ is $\operatorname{defined}$ as $\mathrm{N} \alpha g^{*} \operatorname{sint}(\mathrm{A})=\mathrm{U}$ $\left\{G: G \subseteq A\right.$ and $G$ is $N \alpha g^{*} s$ - open in $\left.\left(U, \tau_{R}(\mathrm{X})\right)\right\}$. That is $\mathrm{N \alpha} g^{*} \operatorname{sint}(\mathrm{A})$ is the union of all $\mathrm{N} \alpha g^{*} s$-open sets contained in A.

Theorem: 3.11 Let A be a nano subset of $\left(U, \tau_{R}(\mathrm{X})\right)$. Then $\mathrm{N} \alpha g^{*} \operatorname{sint}(\mathrm{A})$ is the largest $\mathrm{N} \alpha g^{*} \mathrm{~s}$-open subset of $\left(\mathcal{U}, \tau_{R}(\mathrm{X})\right)$ contained in $\mathrm{A}$ if $\mathrm{A}$ is $\mathrm{N} \alpha g^{*} \mathrm{~s}-$ open.

Proof: Let A be a nano subset of $\left(\mathcal{U}, \tau_{R}(\mathrm{X})\right)$ and be $\mathrm{N} \alpha g^{*} \mathrm{~s}-$ open. Then $\mathrm{N} \alpha g^{*} \operatorname{sint}(\mathrm{A})=\mathrm{U}\left\{G: G \subseteq A\right.$ and $G$ is $\mathrm{N} \alpha g^{*} \mathrm{~s}-$ open in $\left.\left(\mathcal{U}, \tau_{R}(\mathrm{X})\right)\right\}$. Since $\mathrm{A} \subseteq \mathrm{A}$ and $\mathrm{A}$ is $\mathrm{N} \alpha g^{*}$ s -open, $\mathrm{A}=\mathrm{N} \alpha g^{*} \operatorname{sint}(\mathrm{A})$ is the largest $\mathrm{N} \alpha g^{*} \mathrm{~s}$-open subset of $\left(\mathcal{U}, \tau_{R}(\mathrm{X})\right)$ contained in A.

The converse of the above theorem need not be true as seen from the following example.

Example: 3.12 Let $\mathcal{U}=\{a, b, c, d\}, \mathcal{U} / \mathrm{R}=\{\{a\},\{c\},\{b, d\}\}, \mathrm{X}=\{a, b\}$, Let $\mathrm{A}=\{b, c, d\}, \mathrm{N} \alpha g^{*} \operatorname{sint}(\mathrm{A})=\{b, d\}$ is $\mathrm{N} \alpha g^{*}$ s open but $\mathrm{A}=\{b, c, d\}$ is not $\mathrm{N} \alpha g^{*}$ s open.

$$
\tau_{R}(\mathrm{X})=\{\mathcal{U}, \varphi,\{a\},\{a, b, d\},\{b, d\}\}
$$

Remark:3.13 For any subset A of $\left(U, \tau_{R}(\mathrm{X})\right)$, Nint $(\mathrm{A}) \subseteq \mathrm{N} \alpha g^{*} \operatorname{sint}(\mathrm{A}) \subseteq \mathrm{A}$.

Remark:3.14 For a subset $\mathrm{A}$ of $\left(\mathcal{U}, \tau_{R}(\mathrm{X})\right), \operatorname{N} \alpha g^{*} \operatorname{sint}(\mathrm{A}) \neq \operatorname{Nint}(\mathrm{A})$ as seen from the following example.

Example: 3.15 Refer Example:3.6

Let $\mathrm{A}=\{a, c\}, \operatorname{N\alpha } g^{*} \operatorname{sint}(\mathrm{A})=\{a\}$. Nint $(\mathrm{A})=\phi$. 
Hence $\operatorname{N\alpha g} g^{*} \operatorname{sint}(\mathrm{A}) \neq \operatorname{Nint}(\mathrm{A})$.

Remark:3.16 Since every $\mathrm{N} \alpha$ - open set is $\mathrm{N} \alpha g^{*}$ s- open set, every $\mathrm{N} \alpha$ - interior point of a set $\mathrm{A}$ is $\mathrm{N} \alpha g^{*} \mathrm{~s}-$ interior point of A. Thus in general, Noint $(A) \subseteq \mathrm{N} \alpha g^{*} \operatorname{sint}(\mathrm{A})$.

In general $\operatorname{Noint}(A) \neq N \alpha g^{*} \operatorname{sint}(\mathrm{A})$ as seen from the following example.

Example: 3.17 Refer Example:3.6

Let $\mathrm{A}=\{a, c\}, \mathrm{N} \alpha g^{*} \operatorname{sint}(\mathrm{A})=\{a\}, \mathrm{N} \alpha \operatorname{int}(\mathrm{A})=\phi$.

Hence $\mathrm{N} \alpha g^{*} \operatorname{sint}(\mathrm{A}) \neq \mathrm{N} \alpha \operatorname{int}(\mathrm{A})$.

Theorem: 3.18 If $\mathrm{A} \subseteq \mathrm{B}$, then $\mathrm{N} \alpha g^{*} \operatorname{sint}(\mathrm{A}) \subseteq \mathrm{N} \alpha g^{*} \operatorname{sint}(\mathrm{B})$.

Proof: Suppose that $\mathrm{A} \subseteq \mathrm{B}$. We know that $\mathrm{N} \alpha g^{*} \operatorname{sint}(\mathrm{A}) \subseteq \mathrm{A}$. Also we have $\mathrm{A} \subseteq \mathrm{B}$, which implies $\mathrm{N} \alpha g^{*} \operatorname{sint}(\mathrm{A}) \subseteq \mathrm{B}, \mathrm{N} \alpha g^{*} \operatorname{sint}(\mathrm{A})$ is nano open set which is contained in B. But $N \alpha g^{*} \operatorname{sint}(\mathrm{B})$ is the largest nano open set contained in B. Therefore Nag*sint(B) is larger than $\mathrm{N} \alpha g^{*} \operatorname{sint}(\mathrm{A})$. That is $\mathrm{N} \alpha g^{*} \operatorname{sint}(\mathrm{A}) \subseteq \mathrm{N} \alpha g^{*} \operatorname{sint}(\mathrm{B})$

Remark:3.19 $N \alpha g^{*} \operatorname{sint}(\mathrm{A})=\mathrm{N} \alpha g^{*} \operatorname{sint}(\mathrm{B})$ does not imply that $\mathrm{A}=\mathrm{B}$. This is shown by the following example.

Example: 3.20 Refer Example:3.12

Let $\mathrm{A}=\{a, b\}, \mathrm{B}=\{a\} \mathrm{N} \alpha g^{*} \operatorname{sint}(\mathrm{A})=\{a\}=\mathrm{N} \alpha g^{*} \operatorname{sint}(\mathrm{B})$. But $\mathrm{A} \neq \mathrm{B}$.

Theorem: 3.21 For any nano subset $\mathrm{A}$ of $\mathrm{X}$, the following results are true:

1) $\mathrm{N \alpha g}$ sint $(\phi)=\phi$.

2) $\mathrm{N \alpha g}$ sint $(X)=X$.

3) If $\mathrm{A} \subseteq \mathrm{B}$ then $\mathrm{N} \alpha g^{*} \operatorname{sint}(A) \subseteq \mathrm{N} \alpha g^{*} \operatorname{sint}(\mathrm{B})$.

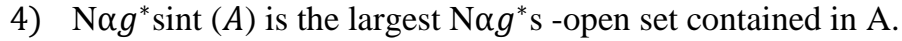

5) $\mathrm{N} \alpha g^{*} \operatorname{sint}(A \cap B)=\mathrm{N} \alpha g^{*} \operatorname{sint}(A) \cap \mathrm{N} \alpha g^{*} \operatorname{sint}(B)$.

6) $\mathrm{N} \alpha g^{*} \operatorname{sint}(A U B) \supseteq \mathrm{N} \alpha g^{*} \operatorname{sint}(\mathrm{A}) \mathrm{U} \mathrm{N} \alpha g^{*} \operatorname{sint}(B)$.

7) $\mathrm{N} \alpha g^{*} \operatorname{sint}\left[\mathrm{N} \alpha g^{*} \operatorname{sint}(A)\right]=\mathrm{N} \alpha g^{*} \operatorname{sint}(A)$

Proof: Proof follows from the definition 3.10

Theorem: 3.22 $\mathrm{A}$ is $\mathrm{N} \alpha g^{*}$ s-open if and only if $\mathrm{N} \alpha g^{*} \operatorname{sint}(A)=A$.

Remark:3.23 For any nano subset $\mathrm{A}$ of $\left(\mathcal{U}, \tau_{R}(\mathrm{X})\right), \operatorname{Nint}(\mathrm{A}) \subseteq \mathrm{N} \alpha g^{*} \operatorname{sint}(A) \subseteq A$.

Theorem: 3.24 For any nano subset $\mathrm{A}$ of $\left(\mathcal{U}, \tau_{R}(\mathrm{X})\right),\left[\mathcal{U}-\mathrm{N} \alpha g^{*} \operatorname{sint}(A)\right]=\operatorname{N\alpha g} g^{*} \operatorname{scl}(\mathcal{U}-\mathrm{A})$.

Proof: Let $\mathrm{x} \in \mathcal{U}-\mathrm{N} \alpha g^{*} \operatorname{sint}(A)$. Then $\mathrm{x} \notin \mathrm{N} \alpha g^{*} \operatorname{sint}(A)$. That is every $\mathrm{N} \alpha g^{*}$ s-open set $\mathrm{G}$ containing $\mathrm{x}$ is such that $\mathrm{G} \not \subset \mathrm{A}$. This implies,

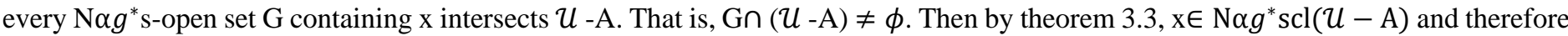
$\left[\mathcal{U}-\mathrm{N} \alpha g^{*} \operatorname{sint}(\mathrm{A})\right] \subseteq \mathrm{N} \alpha g^{*} \operatorname{scl}(\mathcal{U}-\mathrm{A})$.

Conversely, let $\mathrm{x} \in \mathrm{N} \alpha g^{*} \operatorname{scl}(\mathcal{U}-\mathrm{A})$. Then every $\mathrm{N} \alpha g^{*}$ s- open set $\mathrm{G}$ containing $\mathrm{x}$ intersects $\mathcal{U}-\mathrm{A}$. That is, $\mathrm{G} \cap(\mathcal{U}-A)=\phi$.That is,

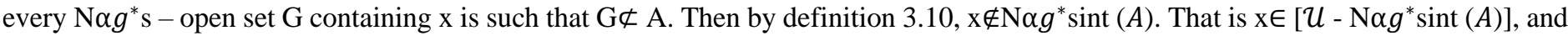
so $\mathrm{N} \alpha g^{*} \operatorname{scl}(\mathcal{U}-\mathrm{A}) \subseteq\left[\mathcal{U}-\mathrm{N} \alpha g^{*} \operatorname{sint}(A)\right]$. Thus $\left[\mathcal{U}-\mathrm{N} \alpha g^{*} \operatorname{sint}(A)\right]=\operatorname{N\alpha } g^{*} \operatorname{scl}(\mathcal{U}-\mathrm{A})$.

Remark:3.25 For any $\mathrm{A} \subseteq X$. we have

1. $\left[\mathcal{U}-\mathrm{N} \alpha g^{*} \operatorname{scl}(\mathcal{U}-\mathrm{A})\right]=\left[\mathrm{N} \alpha g^{*} \operatorname{sint}(A)\right]$

2. $\left[\mathcal{U}-\mathrm{N} \alpha g^{*} \operatorname{sint}(\mathcal{U}-\mathrm{A})\right]=\left[\mathrm{N \alpha} g^{*} \operatorname{scl}(A)\right]$

Taking complement in the above theorem 3.23 and by replacing $\mathrm{A}$ by $\mathcal{U}-\mathrm{A}$ in theorem 3.23 , the above results follow.

Definition: 3.26 A nano subset A of a topological space $\left(\mathcal{U}, \tau_{R}(\mathrm{X})\right)$ is called $\mathrm{N} \alpha g^{*}$ s-neighbourhood (briefly N $\left.\alpha g^{*} \mathrm{~s}-\mathrm{nbd}\right)$ of a point $\mathrm{x}$ of $\mathcal{U}$ if there exists a $\mathrm{N \alpha g}^{*}$ s- open set $\mathrm{U}$ such that $\mathrm{x} \in U \subseteq A$.

Definition:3.27 Let $\left(\mathcal{U}, \tau_{R}(\mathrm{X})\right)$ be a nano topological space and A be a nano subset of $\mathcal{U}$. A nano subset $\mathrm{N}$ of $\mathcal{U}$ is said to be $\mathrm{N} \alpha g^{*}$ s-

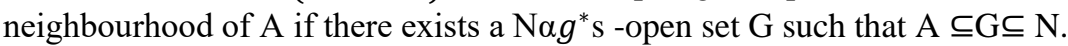

Theorem: 3.28 Let A be a nano subset of a nano topological space $\left(\mathcal{U}, \tau_{R}(\mathrm{X})\right)$. Then $\mathrm{A}$ is $\mathrm{N} \alpha g^{*} \mathrm{~s}-\mathrm{open}$ if and only if $\mathrm{A}$ contains a $\mathrm{N} \alpha g^{*}$ s nbd of each of its points. 
Proof: Let $\mathrm{A}$ be a $\mathrm{N} g^{*}$ s -open set in $\left(\mathcal{U}, \tau_{R}(\mathrm{X})\right)$. Let $\mathrm{x} \in \mathrm{A}$, which implies $\mathrm{x} \in \mathrm{A} \subseteq \mathrm{A}$. Thus $\mathrm{A}$ is $\mathrm{N} g^{*}$ s nbd of $\mathrm{x}$. Hence $\mathrm{A}$ contains a $\mathrm{Nag}{ }^{*}$ s nbd of each of its points.

Conversely, suppose A contains a $N \alpha g^{*}$ s nbd of each of its points. For every x $\in$ A there exists a N $\alpha g^{*}$ s neighbourhood $N_{x}$ of x such

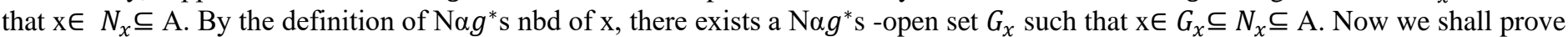
that $\mathrm{A}=\mathrm{U}\left\{G_{x}: \mathrm{x} \in \mathrm{A}\right\}$. Let $\mathrm{x} \in \mathrm{A}$. Then there exists $\mathrm{N} \alpha g^{*}$ s -open set $G_{x}$ such that $\mathrm{x} \in G_{x}$. Therefore,

$\mathrm{x} \in \mathrm{U}\left\{G_{x}: \mathrm{x} \in \mathrm{A}\right\}$ which implies $\mathrm{A} \subseteq \mathrm{U}\left\{G_{x}: \mathrm{x} \in \mathrm{A}\right\}$. Now let $\mathrm{y} \in \mathrm{U}\left\{G_{x}: \mathrm{x} \in \mathrm{A}\right\}$ so that $\mathrm{y} \in$ some $G_{x}$ for some $\mathrm{x} \in A$ and hence $\mathrm{y} \in A$. SoU $\left\{G_{x}: \mathrm{x} \in \mathrm{A}\right\} \subseteq \mathrm{A}$ Hence $\mathrm{A}=\mathrm{U}\left\{G_{x}: \mathrm{x} \in \mathrm{A}\right\}$. Also each $G_{x}$ is a Nag*s-open set and hence $\mathrm{A}$ is a Nag*s -open set.

Theorem: 3.29 If $\mathrm{A}$ is a N $\alpha g^{*} \mathrm{~s}$ - closed set of $\left(\mathcal{U}, \tau_{R}(\mathrm{X})\right)$ and $\mathrm{x} \in \mathrm{X}-\mathrm{A}$, then there exists a $N \alpha g^{*} \mathrm{~s}$ nbd $\mathrm{N}$ of $\mathrm{x}$ such that $\mathrm{N} \cap \mathrm{A}=\phi$. Proof: If A is a $\mathrm{Nag}^{*}$ s -closed set in X, then X-A is a Nag*s -open set. By theorem 3.27, $U$-A contains a Nag*s nbd of each of its points, which implies that, there exists a $\mathrm{N} \alpha g^{*} \mathrm{~s}$ nbd of $\mathrm{N}$ of $\mathrm{x}$ such that $\mathrm{N} \subseteq \mathcal{U}$-A. That is, no point of $\mathrm{N}$ belongs to $\mathrm{A}$ and hence $\mathrm{N} \cap \mathrm{A} \neq$ $\phi$.

Theorem: 3.30 Let $\left(\mathcal{U}, \tau_{R}(\mathrm{X})\right)$ be a nano topological space. If $\mathrm{A}$ is a Nag${ }^{*} \mathrm{~s}$-closed subset of $\left(\mathcal{U}, \tau_{R}(\mathrm{X})\right)$ and $\mathrm{x} \in \mathcal{U}$-A then there exists a Nag${ }^{*} \mathrm{~s}$-neighbourhood $\mathrm{N}$ of $\mathrm{X}$ such that $\mathrm{A} \cap \mathrm{N} \neq \phi$.

Proof: Since A is $\mathrm{N} g^{*} \mathrm{~s}$ - closed, $\mathcal{U}$-A is $\mathrm{N} g^{*} \mathrm{~s}$-open set in $\left(\mathcal{U}, \tau_{R}(\mathrm{X})\right)$. By theorem 3.27, $\mathcal{U}$-A contains a N $\alpha g^{*} \mathrm{~s}-$ neighbourhood of each of its points. Hence there exists a $\mathrm{N} \alpha g^{*} \mathrm{~s}$-neighbourhood of $\mathrm{N}$ of $\mathrm{x}$ such that $\mathrm{N} \subseteq \mathcal{U}$-A. Then $\mathrm{N} \cap \mathrm{A} \neq \phi$.

Definition:3.31 Let $\left(\mathcal{U}, \tau_{R}(\mathrm{X})\right)$ be a nano topological space and A be a nano subset of $\left(\mathcal{U}, \tau_{R}(\mathrm{X})\right)$. Then a point $\mathrm{x} \in \mathcal{U}$ is called a N $\alpha g^{*} \mathrm{~s}$

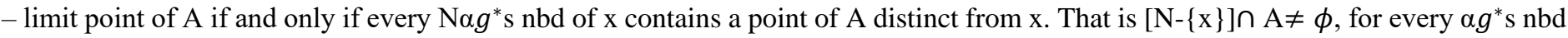

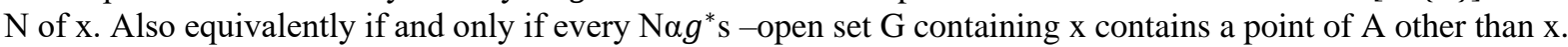

Theorem: 3.32 Let A and B be nano subsets of $\left(U, \tau_{R}(X)\right)$. Then $A \subseteq B$ implies $N \alpha g^{*}$ sd $(A) \subseteq N \alpha g^{*}$ sd (B).

Proof: Let $\mathrm{x} \in \mathrm{N} \alpha g^{*} \mathrm{sd}(\mathrm{A})$ implies $\mathrm{x}$ is a Nag* s -limit point of A. That is every $\mathrm{N} \alpha g^{*}$ s nbd of $\mathrm{x}$ contains a point of A other than $\mathrm{x}$. Since

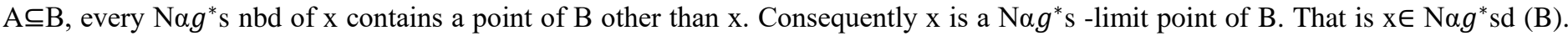

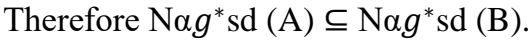

Therem:3.33 Let $\left(\mathcal{U}, \tau_{R}(\mathrm{X})\right)$ be a nano topological space and A be a nano subset of $\left(\mathcal{U}, \tau_{R}(\mathrm{X})\right)$. Then $\mathrm{A}$ is $\mathrm{N} \alpha g^{*} \mathrm{~s}$-closed if and only if $\mathrm{Nag}^{*} \mathrm{~s} \mathrm{~d}(\mathrm{~A}) \subseteq \mathrm{A}$.

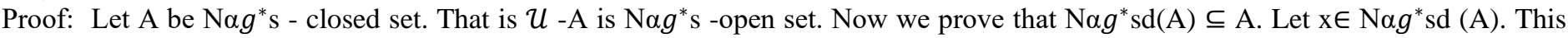
implies $\mathrm{x}$ is a Nag${ }^{*} \mathrm{~s}$-limit point of A. That is every Nag${ }^{*} \mathrm{~s} n b d$ of $\mathrm{x}$ contains a point of A different from $\mathrm{x}$. Now suppose $\mathrm{x} \notin \mathrm{A}$ so that $\mathrm{x} \in \mathcal{U}$-A, which is $\mathrm{N} g^{*}$ s -open and by definition by Nag${ }^{*}$ s- open sets, there exists a $\mathrm{N} \alpha g^{*}$ s nbd $\mathrm{N}$ of $\mathrm{x}$ such that $\mathrm{N} \subseteq \mathcal{U}$-A. From this we conclude that $\mathrm{N}$ contains no point of $\mathrm{A}$, which is a contradiction. Therefore $\mathrm{x} \in A$ and hence $\mathrm{N} \alpha g^{*} \mathrm{sd}(\mathrm{A}) \subseteq \mathrm{A}$.

Conversely, assume that ${\mathrm{N} \alpha g^{*}}^{*} \mathrm{sd}(\mathrm{A}) \subseteq \mathrm{A}$. We will prove that $\mathrm{A}$ is a $\alpha g^{*}$ s-closed set in $\left(\mathcal{U}, \tau_{R}(\mathrm{X})\right)$ or $\mathcal{U}-\mathrm{A}$ is $N \alpha g^{*}$ s-open set. Let $\mathrm{x}$ be an arbitrary point of $U-\mathrm{A}$, so that $\mathrm{x} \notin A$ which implies that $\mathrm{x} \notin \mathrm{N} \alpha g^{*} \mathrm{sd}(\mathrm{A})$. That is there exists a $\mathrm{N} \alpha g^{*} \mathrm{~s}$ nbd $\mathrm{N}$ of $\mathrm{x}$ which consists of only points of $\mathcal{U}$-A. This means that $\mathcal{U}-\mathrm{A}$ is $\mathrm{N}_{\alpha g^{*}}$ s- open and hence $\mathrm{A}$ is $\operatorname{Nag}^{*} \mathrm{~s}$-closed set in $\left(\mathcal{U}, \tau_{R}(\mathrm{X})\right)$.

Therem:3.34 Let $\left(\mathcal{U}, \tau_{R}(\mathrm{X})\right)$ be a nano topological space. Then every $\mathrm{N} \alpha g^{*}$ s-derived set in $\left(\mathcal{U}, \tau_{R}(\mathrm{X})\right)$ is $\mathrm{N} \alpha g^{*}$ s-closed set.

Proof: Let A be a nano subset of $\left(U, \tau_{R}(\mathrm{X})\right)$ and $\mathrm{Nag}^{*}$ sd (A) be Nag*${ }^{*}$ s-derived set of A. By theorem 3.33, A is Nag${ }^{*}$ s-closed if and

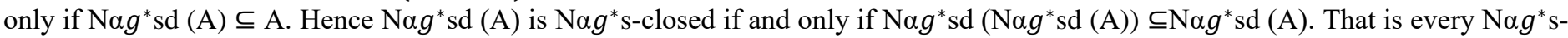
limit point of ${\mathrm{N} \alpha g^{*}}^{*} \mathrm{sd}(\mathrm{A})$ belongs to $\mathrm{N} \alpha g^{*} \mathrm{sd}(\mathrm{A})$.

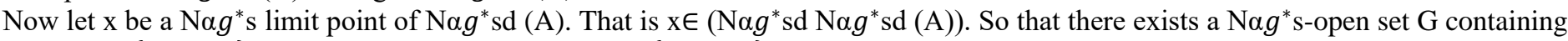
x such that $\{G-\{x\}\} \cap N \alpha g^{*} s d(A) \neq \phi$ which implies $\left.\{G-\{x\}\} \cap A\right) \neq \phi$, because every Nag*s nbd of an element of $N \alpha g^{*} \operatorname{sd}(\mathrm{A})$ has at least one point of A. Hence $\mathrm{x}$ is a ${\mathrm{N} \alpha g^{*}}^{*}$ - limit point of A. That is $\mathrm{x}$ belongs to $\mathrm{N} \alpha g^{*} \operatorname{sd}(\mathrm{A})$.

Thus $\mathrm{x} \in \mathrm{N} \alpha g^{*} \operatorname{sd}\left(\mathrm{N} \alpha g^{*} \operatorname{sd}(\mathrm{A})\right)$ implies $\mathrm{x} \in \mathrm{N} \alpha g^{*} \operatorname{sd}(\mathrm{A})$. Therefore $\mathrm{N} \alpha g^{*} \operatorname{sd}(\mathrm{A})$ is $\mathrm{N} \alpha g^{*} \mathrm{~s}-$ closed set in $\left(\mathcal{U}, \tau_{R}(\mathrm{X})\right)$.

\section{APPLICATIONS OF $\mathbf{N} \boldsymbol{\alpha} \boldsymbol{g}^{*}$ S CLOSED SETS}

In this section we introduce four new spaces namely; $\mathrm{N} T_{\alpha g s}^{*}$ spaces, $N^{*} T_{\alpha g s}$ spaces, $N_{\alpha g s} T^{*}$ spaces, and $N_{\alpha g s} T_{\frac{1}{2}}^{*}$ spaces as applications in nano topological spaces and study some of their properties.

Definition: 4.1 A nano technological space $\left(\mathcal{U}, \tau_{R}(\mathrm{X})\right)$ is said to be a $\mathrm{N} T_{\alpha g s}^{*}$ space if every $\mathrm{N} \alpha g^{*}$ s closed set is nano semi closed.

Example: 4.2 Let $\mathcal{U}=\{a, b, c\}, \mathcal{U} / \mathrm{R}=\{\{a\},\{b, c\}\}, \mathrm{X}=\{a\}, \tau_{R}(\mathrm{X})=\{\mathcal{U}, \varphi,\{a\}\}$

Here every $\mathrm{N} \alpha g^{*}$ s closed set is nano semi closed. Hence $\left(\mathcal{U}, \tau_{R}(\mathrm{X})\right)$ is $\mathrm{N} T_{\alpha g s}^{*}$ space.

Theorem: 4.3 If a space $\left(\mathcal{U}, \tau_{R}(\mathrm{X})\right)$ is $\mathrm{N} T_{\alpha g s}^{*}$ - space, then every singleton of $\left(\mathcal{U}, \tau_{R}(\mathrm{X})\right)$ is either Ngs-closed or nano semi open. 
Proof: Let $\mathrm{x} \in \mathrm{X}$ and suppose that $\{\mathrm{x}\}$ is not a Ngs-closed set of $\left(\mathcal{U}, \tau_{R}(\mathrm{X})\right)$. This implies $\{\mathrm{x}\}^{\mathrm{c}}$ is not $\mathrm{N} g \mathrm{~s}$-open. So $\mathcal{U}$ is the only $\mathrm{Ngs}$ open set containing $\{\mathrm{x}\}^{\mathrm{c}}$. Then $\{\mathrm{x}\}^{\mathrm{c}}$ is $N \alpha g^{*} \mathrm{~s}$ - nano closed set of $\left(\mathcal{U}, \tau_{R}(\mathrm{X})\right)$. Since $\left(\mathcal{U}, \tau_{R}(\mathrm{X})\right)$ is a $\mathrm{N} T_{\alpha g s}^{*}$-space, $\{\mathrm{x}\}^{\mathrm{c}}$ is nano semiclosed or equivalently $\{\mathrm{x}\}$ is nano semi -open in $\left(\mathcal{U}, \tau_{R}(\mathrm{X})\right)$.

Theorem: 4.4 Every $\mathrm{N} T_{b}$ - space is $\mathrm{N} T_{\alpha g s}^{*}$-space but not conversely.

Proof: Let $\left(\mathcal{U}, \tau_{R}(\mathrm{X})\right)$ be a $\mathrm{N} T_{b}$ - space. Let A be a $\mathrm{N} \alpha g^{*}$ s- closed set of $\left(\mathcal{U}, \tau_{R}(\mathrm{X})\right)$. By theorem, "Every N $\alpha g^{*}$ s closed set is Ngs-closed set", A is Ngs-closed set. Since $\left(U, \tau_{R}(\mathrm{X})\right)$ is $\mathrm{N} T_{b}$-space, A is nano closed and so it is nano semi-closed in $\left(\mathcal{U}, \tau_{R}(\mathrm{X})\right)$. Therefore $\left(\mathcal{U}, \tau_{R}(\mathrm{X})\right)$ is $\mathrm{N} T_{\alpha g s}^{*}$-space.

Example: 4.5 Refer Example: 4.2

$\left(\mathcal{U}, \tau_{R}(\mathrm{X})\right)$ is $\mathrm{N} T_{\alpha g s}^{*}$ space but not a $\mathrm{N} T_{b}$ space.

Theorem:4.6 Every $\mathrm{N} T_{b}^{*}$-space is $\mathrm{N} T_{\alpha g s}^{*}$ but not conversely.

Proof: Let $\left(\mathcal{U}, \tau_{R}(\mathrm{X})\right)$ be a $\mathrm{N} T_{b}^{*}$-space. Let A be a N $\alpha g^{*} \mathrm{~s}$ - closed set of $\left(\mathcal{U}, \tau_{R}(\mathrm{X})\right)$. By theorem, "Every $\mathrm{N} \alpha g^{*} \mathrm{~s}$-closed set is $\mathrm{N} g^{*} \mathrm{~s}$ closed set". A is $\mathrm{N}^{*}$ s- closed set. Since $\left(\mathcal{U}, \tau_{R}(\mathrm{X})\right)$ is $T_{b}^{*}$-space, A is nano closed and so it is nano semi-closed in $\left(\mathcal{U}, \tau_{R}(\mathrm{X})\right)$. Therefore $\left(\mathcal{U}, \tau_{R}(\mathrm{X})\right)$ is $\mathrm{N} T_{\alpha g s^{-}}^{*}$ space.

Example: 4.7 Refer Example: 4.2

$\left(\mathcal{U}, \tau_{R}(\mathrm{X})\right)$ is $\mathrm{N} T_{\alpha g s^{-}}^{*}$ space but not a $\mathrm{N} T_{b}^{*}$ space.

Theorem: 4.8 Every $\mathrm{N} T_{b}^{* *}$-space is $\mathrm{N} T_{\alpha g s^{-}}^{*}$ space but not conversely.

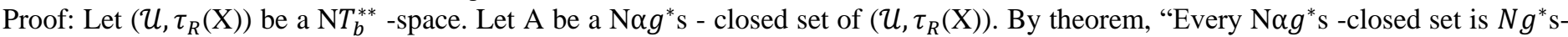
closed set". A is $\mathrm{N}^{*}$ s- closed set. Since $\left(U, \tau_{R}(\mathrm{X})\right)$ is $\mathrm{N} T_{b}^{* *}$-space, $\mathrm{A}$ is $\mathrm{N} \alpha$-closed. Since every $\mathrm{N} \alpha$-closed set is nano semi-closed, then $\mathrm{A}$ is nano semi closed in $\left(\mathcal{U}, \tau_{R}(\mathrm{X})\right)$. Therefore $\left(\mathcal{U}, \tau_{R}(\mathrm{X})\right)$ is $\mathrm{N} T_{\alpha g s^{-}}^{*}$ space.

Example: 4.9 Let $\mathcal{U}=\{a, b, c, d\}, \mathcal{U} / \mathrm{R}=\{\{a\},\{c\},\{b, d\}\}, \mathrm{X}=\{a, b\}, \tau_{R}(\mathrm{X})=\{\mathcal{U}, \varphi,\{a\},\{b, d\}\},\left(\mathcal{U}, \tau_{R}(\mathrm{X})\right)$ is $\mathrm{N} T_{\alpha g s}^{*}$ space but not $\mathrm{N} T_{b}^{* *}-$ space.

Theorem: 4.10 Every semi- $\mathrm{N} T_{\frac{1}{2}}$ - space is $\mathrm{N} T_{\alpha g s^{-}}^{*}$ space but not conversely.

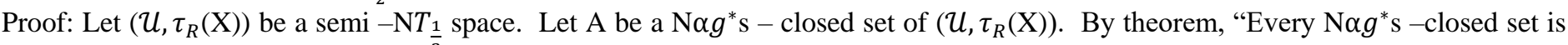
Nsg - closed set". A is Nsg-closed set. Since $\left(U, \tau_{R}(X)\right)$ is semi-N $T_{\frac{1}{2}}$ space, A is nano semi-closed in $\left(U, \tau_{R}(\mathrm{X})\right)$. Therefore $\left(U, \tau_{R}(\mathrm{X})\right)$ is $\mathrm{NT}_{\alpha g s^{*}}^{*}$-space.

Example: 4.11 Refer Example: 4.9

$\left(\mathcal{U}, \tau_{R}(\mathrm{X})\right)$ is $\mathrm{N} T_{\alpha g s^{-}}^{*}$ space but not semi- $\mathrm{N} T_{\frac{1}{2}}$ space.

Theorem: 4.12 Every $N_{\alpha} T_{b}$-space is is $N T_{\alpha g s}^{*}$ - space but not conversely.

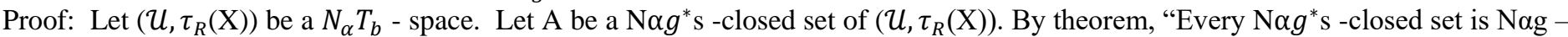
closed set". A is Nag - closed set. Since $\left(\mathcal{U}, \tau_{R}(\mathrm{X})\right)$ is $N_{\alpha} T_{b}$ - space, A is nano closed. Since every nano closed set is nano semi-closed, then $\mathrm{A}$ is nano semi-closed in $\left(\mathcal{U}, \tau_{R}(\mathrm{X})\right)$. Therefore $\left(\mathcal{U}, \tau_{R}(\mathrm{X})\right)$ is $N T_{\alpha g s}^{*}$ - space.

Example: 4.13 Refer Example: 4.2

$\left(\mathcal{U}, \tau_{R}(\mathrm{X})\right)$ is $N T_{\alpha g s}^{*}$ space but not $N_{\alpha} T_{b}$ space.

Definition: 4.14 A nano topological space $\left(U, \tau_{R}(\mathrm{X})\right)$ is said to be a $N^{*} T_{\alpha g s}$ - space if every $N \alpha g^{*}$ s -closed set is $\mathrm{N} \alpha$-closed.

Example: 4.15 Refer Example: 4.9

$\left(\mathcal{U}, \tau_{R}(\mathrm{X})\right)$ is $N^{*} T_{\alpha g s}$ space.

Theorem: 4.16 Every $N^{*} T_{\alpha g s}$ - space is $N T_{\alpha g s}^{*}$ - space.

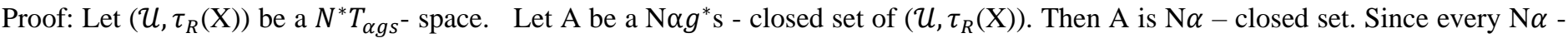
closed set is nano semi-closed, then $\mathrm{A}$ is nano semi closed in $\left(\mathcal{U}, \tau_{R}(\mathrm{X})\right)$. Therefore $\left(\mathcal{U}, \tau_{R}(\mathrm{X})\right)$ is $N T_{\alpha g s}^{*}$ space.

Theorem: 4.17 Every $\mathrm{N} T_{b^{-}}$space is $N^{*} T_{\alpha g s^{-}}$space but not conversely. 


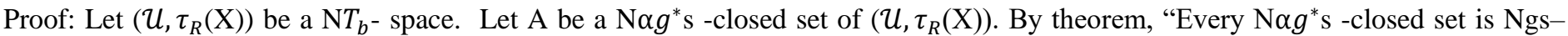
closed set". A is Ngs - closed set. Since $\left(U, \tau_{R}(\mathrm{X})\right)$ is $\mathrm{N} T_{b}$ - space, A is nano closed and so it is $\mathrm{N} \alpha$ - closed in $\left(U, \tau_{R}(\mathrm{X})\right)$. Therefore $\left(\mathcal{U}, \tau_{R}(\mathrm{X})\right)$ is

$N^{*} T_{\alpha g s}$ - space.

Example: 4.18 Refer Example: 4.2

$\left(\mathcal{U}, \tau_{R}(\mathrm{X})\right)$ is $N^{*} T_{\alpha g s}$ space but not $\mathrm{N} T_{b}$ space.

Theorem: 4.19 Every $\mathrm{N} T_{b}^{*}$ - space is $N^{*} T_{\alpha g s^{-}}$space but not conversely.

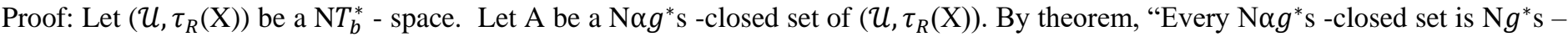
closed set". A is $\mathrm{N} g^{*} \mathrm{~s}$ - closed set. Since $\left(\mathcal{U}, \tau_{R}(\mathrm{X})\right)$ is $\mathrm{N} T_{b}^{*}$ - space, A is nano closed and so it is $\mathrm{N} \alpha-\operatorname{closed}$ in $\left(\mathcal{U}, \tau_{R}(\mathrm{X})\right)$. Therefore $\left(\mathcal{U}, \tau_{R}(\mathrm{X})\right)$ is $N^{*} T_{\alpha g s}$ - space.

Example: 4.20 Refer Example: 4.2

$\left(\mathcal{U}, \tau_{R}(\mathrm{X})\right)$ is $N^{*} T_{\alpha g s}$ space but not $\mathrm{N} T_{b}^{*}$ space.

Theorem:4.21 A space $\left(\mathcal{U}, \tau_{R}(\mathrm{X})\right)$ is $N^{*} T_{\alpha g s}$ - space if and only if every singleton of $\left(\mathcal{U}, \tau_{R}(\mathrm{X})\right)$ is either Ngs- closed or $\mathrm{N} \alpha-$ open. Proof: Let $\mathrm{x} \in \mathcal{U}$ and suppose that $\{\mathrm{x}\}$ is not a Ngs- closed set of $\left(\mathcal{U}, \tau_{R}(\mathrm{X})\right)$. This implies $\{\mathrm{x}\}^{\mathrm{c}}$ is not Ngs open. So $\mathcal{U}$ is the only Ngs open set containing $\{\mathrm{x}\}^{\mathrm{c}}$.Then $\{\mathrm{x}\}^{\mathrm{c}}$ is $\mathrm{N \alpha g}^{*} \mathrm{~s}$-closed set of $\left(\mathcal{U}, \tau_{R}(\mathrm{X})\right)$. Since $\left(\mathcal{U}, \tau_{R}(\mathrm{X})\right)$ is a $N^{*} T_{\alpha g s}$-space $\left(\mathcal{U}, \tau_{R}(\mathrm{X})\right)$ is a $N^{*} T_{\alpha g s^{-}}$ space $\{\mathrm{x}\}^{\mathrm{c}}$ is $\mathrm{N} \alpha$-closed or equivalently $\{\mathrm{x}\}$ is $\mathrm{N} \alpha$ - open in $\left(\mathcal{U}, \tau_{R}(\mathrm{X})\right)$. Conversely, let A be a N $\alpha g^{*} \mathrm{~s}$-closed set of $\left(\mathcal{U}, \tau_{R}(\mathrm{X})\right)$. Trivially $\mathrm{A} \subseteq \mathrm{N} \alpha \mathrm{cl}(\mathrm{A})$. Let $\mathrm{x} \in \mathrm{N} \alpha \mathrm{cl}(\mathrm{A})$. By hypothesis, $\{\mathrm{x}\}$ is either $\mathrm{Ngs}-$ closed or $\mathrm{N} \alpha$-open.

Case:(i) Suppose $\{\mathrm{x}\}$ is Ngs -closed. By theorem, "A nano subset A is an $N \alpha g^{*} \mathrm{~s}$-closed set in $\left(\mathcal{U}, \tau_{R}(\mathrm{X})\right)$ if and only if $\operatorname{Nacl}(\mathrm{A})$-A contains no non-empty Ngs-closed set in $\left(\mathcal{U}, \tau_{R}(\mathrm{X})\right)$ " $\mathrm{Nacl}(\mathrm{A})$-A does not certain any non-empty $\mathrm{Ngs}-$ closed set in $\left(\mathcal{U}, \tau_{R}(\mathrm{X})\right)$. If $\mathrm{x} \notin \mathrm{A}$, then $\{\mathrm{x}\} \subseteq \mathrm{N} \alpha \mathrm{cl}(\mathrm{A})-\mathrm{A}$. But this is not possible according to the theorem, as $\mathrm{A}$ is $\mathrm{N} \alpha g^{*}$ s -closed set. Therefore $\mathrm{x} \in \mathrm{A}$.

Case: (ii) Suppose $\{x\}$ is N $\alpha$-open. Since $x \in \operatorname{Nacl}(A)$. then $\{x\} \cap A \neq \phi$. So $x \in A$. Thus in any case $x \in A$. So Nacl (A) $\subseteq A$. Therefore $\mathrm{A}=\mathrm{N} \alpha \mathrm{cl}(\mathrm{A})$ or equivalently $\mathrm{A}$ is $\mathrm{N} \alpha$-closed. Therefore $\left(\mathcal{U}, \tau_{R}(\mathrm{X})\right)$ is $N^{*} T_{\alpha g s}$-space.

Definition: 4.22 A topological space $\left(U, \tau_{R}(\mathrm{X})\right)$ is said to be a $N_{\alpha g s} T^{*}$-space if every nano semi-closed is $N \alpha g^{*}$ s -closed.

Example: 4.23 Refer Example: 4.2

$\left(\mathcal{U}, \tau_{R}(\mathrm{X})\right)$ is $N_{\alpha g_{s}} T^{*}$ space.

Theorem:4.24 Every $\mathrm{N}_{b^{-}}$- space is $N_{\alpha g s} T^{*}$-- space but not conversely.

Proof: Let $\left(\mathcal{U}, \tau_{R}(\mathrm{X})\right)$ be a NT$T_{b}$-space. Let A be nano semi-closed set of $\left(\mathcal{U}, \tau_{R}(\mathrm{X})\right)$. Then $\mathrm{A}$ is $\mathrm{Ngs}-\operatorname{closed}$ set in $\left(\mathcal{U}, \tau_{R}(\mathrm{X})\right)$. Since $\left(\mathcal{U}, \tau_{R}(\mathrm{X})\right)$ is $\mathrm{N} T_{b}$-space, A is nano closed and so it is $\mathrm{N} \alpha g^{*} \mathrm{~s}-\operatorname{closed}$ in $\left(\mathcal{U}, \tau_{R}(\mathrm{X})\right)$. Therefore $\left(\mathcal{U}, \tau_{R}(\mathrm{X})\right)$ is $N_{\alpha g s} T^{*}$ - space.

Example: 4.25 Refer Example: 4.2

$\left(\mathcal{U}, \tau_{R}(\mathrm{X})\right)$ is $N_{\alpha g s} T^{*}$ space but not $\mathrm{N} T_{b}$ space.

Theorem: 4.26 If a space $\left(\mathcal{U}, \tau_{R}(\mathrm{X})\right)$ is $N_{\alpha g s} T^{*}$ - space, then every singleton of $\left(\mathcal{U}, \tau_{R}(\mathrm{X})\right)$ is either Nsg- open or N $\alpha g^{*} \mathrm{~s}$-closed. Proof: Let $\mathrm{x} \in \mathrm{X}$ and suppose that $\{\mathrm{x}\}$ is not a Nsg-open set of $\left(\mathcal{U}, \tau_{R}(\mathrm{X})\right)$. Then $\{\mathrm{x}\}^{\mathrm{c}}$ is not Nsg-closed. By theorem, we have $\{\mathrm{x}\}$ is semi-closed. Since $\left(\mathcal{U}, \tau_{R}(\mathrm{X})\right)$ is $N_{\alpha g s} T^{*}$-space, $\{\mathrm{x}\}$ is $N \alpha g^{*}$ s-closed in $\left(\mathcal{U}, \tau_{R}(\mathrm{X})\right)$.

Definition: 4.27 A topological space $\left(\mathcal{U}, \tau_{R}(\mathrm{X})\right)$ is said to be a $N_{\alpha g s} T_{\frac{1}{2}}^{*}$-space if every $\mathrm{N} \alpha g^{*} s$ closed set is nano closed.

Example: 4.28 Refer Example: 4.9

$\left(\mathcal{U}, \tau_{R}(\mathrm{X})\right)$ is $N_{\alpha g s} T_{\frac{1}{2}}^{*}$ space.

Theorem: 4.29 Every $\mathrm{N} T_{b}$-space is $N_{\alpha g s} T_{\frac{1}{2}}^{*}$ space but not conversely.

Proof: Let $\left(U, \tau_{R}(\mathrm{X})\right)$ be a $\mathrm{N} T_{b}$-space. Let A be a N $\alpha g^{*}$ s -closed set of $\left(\mathcal{U}, \tau_{R}(\mathrm{X})\right)$. By theorem, "Every $\mathrm{N} \alpha g^{*} \mathrm{~s}$-closed set is Ngs-closed set", A is Ngs-closed set. Since $\left(\left(\mathcal{U}, \tau_{R}(\mathrm{X})\right)\right.$ is $\mathrm{N} T_{b}$-space, A is nano closed in $\left(\mathcal{U}, \tau_{R}(\mathrm{X})\right)$. Therefore $\left(\mathcal{U}, \tau_{R}(\mathrm{X})\right)$ is $N_{\alpha g s} T_{\frac{1}{2}}^{*}$ space.

Example: 4.30 Refer Example: 4.9

$\left(\mathcal{U}, \tau_{R}(\mathrm{X})\right)$ is $N_{\alpha g s} T_{\frac{1}{2}}^{*}$ space but not $\mathrm{N} T_{b}$ space. 
Theorem: 4.31 Every $\mathrm{N} T_{b}^{*}$-space is $N_{\alpha g s} T_{\frac{1}{2}}^{*}$ space but not conversely.

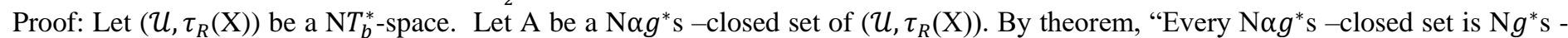
closed set", A is $\mathrm{Ng}^{*}$ s-closed set. Since $\left(\mathcal{U}, \tau_{R}(\mathrm{X})\right)$ is $\mathrm{N}_{b}^{*}$-space, A is nano closed in $\left(\mathcal{U}, \tau_{R}(\mathrm{X})\right)$. Therefore $\left(\mathcal{U}, \tau_{R}(\mathrm{X})\right)$ is $N_{\alpha g s} T_{\frac{1}{2}}^{*}$ space.

Example: 4.32 Refer Example: 4.9

$\left(\mathcal{U}, \tau_{R}(\mathrm{X})\right)$ is $N_{\alpha g s} T_{\frac{1}{2}}^{*}$ space but not $\mathrm{N} T_{b}^{*}$ space.

Theorem: 4.33 Every $N_{\alpha g s} T_{\frac{1}{2}}^{*}$-space is $N T_{\alpha g s}^{*}$-space but not conversely.

Proof: Let $\left(\mathcal{U}, \tau_{R}(\mathrm{X})\right)$ be a $N_{\alpha g s} T_{\frac{1}{2}}^{*}$ space. Let $\mathrm{K}$ be a $N \alpha g^{*} \mathrm{~s}-\operatorname{closed}$ set of $\left(\mathcal{U}, \tau_{R}(\mathrm{X})\right)$. Then $\mathrm{K}$ is nano closed in $\left(\mathcal{U}, \tau_{R}(\mathrm{X})\right)$. So $\mathrm{K}$ is nano semi-closed in $\left(\mathcal{U}, \tau_{R}(\mathrm{X})\right)$. Therefore $\left(\mathcal{U}, \tau_{R}(\mathrm{X})\right)$ is $N T_{\alpha g s}^{*}$-space.

Example: 4.34 Refer Example: 4.2

$\left(\mathcal{U}, \tau_{R}(\mathrm{X})\right)$ is $N T_{\alpha g s}^{*}$ space but not $N_{\alpha g s} T_{\frac{1}{2}}^{*}$ space.

Theorem: 4.35 Every $N_{\alpha g s} T_{\frac{1}{2}}^{*}$-space is $N^{*} T_{\alpha g s}$-space but not conversely.

Proof: Let $\left(\mathcal{U}, \tau_{R}(\mathrm{X})\right)$ be a $N_{\alpha g s} T_{\frac{1}{2}}^{*}$-space. Let $\mathrm{K}$ be a $N \alpha g^{*} \mathrm{~s}-$ closed set of $\left(\mathcal{U}, \tau_{R}(\mathrm{X})\right)$. Then $\mathrm{K}$ is closed in $\left(\mathcal{U}, \tau_{R}(\mathrm{X})\right)$. So $\mathrm{K}$ is $\mathrm{N} \alpha-$ closed in $\left(\mathcal{U}, \tau_{R}(\mathrm{X})\right)$. Therefore $\left(\mathcal{U}, \tau_{R}(\mathrm{X})\right)$ is $N^{*} T_{\alpha g s}$-space.

Example: 4.36 Refer Example: 4.2

$\left(\mathcal{U}, \tau_{R}(\mathrm{X})\right)$ is $N^{*} T_{\alpha g s}$ space but not $N_{\alpha g s} T_{\frac{1}{2}}^{*}$ space.

Theorem: 4.37 If a space $\left(\mathcal{U}, \tau_{R}(\mathrm{X})\right)$ is $N_{\alpha g s} T_{\frac{1}{2}}^{*}$-space, then every singleton of $\left(\mathcal{U}, \tau_{R}(\mathrm{X})\right)$ is either Ngs -closed or open.

Proof: Let $\mathrm{x} \in \mathrm{X}$ and suppose that $\{\mathrm{x}\}$ is not a Ngs- closed set of $\left(\mathcal{U}, \tau_{R}(\mathrm{X})\right)$. This implies $\{\mathrm{x}\}^{\mathrm{c}}$ is not a Ngs -open. So $\mathcal{U}$ is the only Ngsopen set containing $\{\mathrm{x}\}^{\mathrm{c}}$. Then $\{\mathrm{x}\}^{\mathrm{c}}$ is $N \alpha g^{*}$ s closed set of $\left(\mathcal{U}, \tau_{R}(\mathrm{X})\right)$. Since $\left(\mathcal{U}, \tau_{R}(\mathrm{X})\right)$ is a $N_{\alpha g s} T_{\frac{1}{2}}^{*}$ space, $\{\mathrm{x}\}^{\mathrm{c}}$ is closed or equivalently $\{\mathrm{x}\}$ is open in $\left(\mathcal{U}, \tau_{R}(\mathrm{X})\right)$

Example: 4.38 Refer Example: 4.2

In $\left(\mathcal{U}, \tau_{R}(\mathrm{X})\right)$ every singleton is either $\mathrm{Ngs}$ closed or $\mathrm{Ngs}$ open but $\{b\}$ is $\mathrm{N \alpha g}{ }^{*}$ s closed but not closed.

\section{REFERENCES}

[1] S.P. Arya and T.M. Nour, "Characterization of subnormal spaces, "Indian J. Pure Appl. Math. 21(8) (1990),717-719.

[2] M.Dharani,V.Senthilkumaran and Y.Palaniappan,”On nano $\alpha \mathrm{g}^{\wedge *} \mathrm{~s}$ closed sets in topological spaces”, Annals of Pure and Applied Mathematics,Submitted.

[3] M. Lellis Thivagar and Carmel Richard, "Weak forms of nano continuity", IISTE 3 (2013) No 7.

[4] M. Lellis Thivagar and V. Sutha Devi "On Multigranular nano topology" (2015) south East Asain Bulletin of Mathematics, Springer Verlag

[5] N. Levine, "Generalized closed sets in topology, "Rend,Circ.Math.Palermo 19(2) (1970) 89-76.

[6] A.S. Mashour, M.E. Abd-el-monsef and S.N. Eldeeb, “ $\alpha$ continuous and $\alpha$ open mappings, "Acta Math Hung. 41(34) (1983) $213-218$.

[7] O. Njastad, "On some classes of nearly open sets, "Pacific. J. Math 15(1965) 961-970.

[8] T.D. Rayana gouder, "On some recent topics in topology” Ph.D, thesis, Karnatak University (2007).

\section{AUTHORS}

First Author - M. Dharani, M.Phil Scholar, Aringar Anna Government Arts college, Musiri-621211, Tamilnadu, India., Email: jodharu@gmail.com

Second Author - V. Senthilkumaran, Associate Professor of Mathematics, Aringar Anna Government Arts college, Musiri-621211, Tamilnadu, India., Email: vsenthil1966@gmail.com

Third Author - Y. Palaniappan, Associate Professor of Mathematics (Retd), Aringar Anna Government Arts college, Musiri-621211, Tamilnadu, India.,Email: palaniappany48@gmail.com 
International Journal of Scientific and Research Publications, Volume 11, Issue 10, October 2021

This publication is licensed under Creative Commons Attribution CC BY. 